determine the differences in use of resources by accident and emergency (A\&E) primary care attenders between inner London and Eastbourne, and yet data relating to resource use were not collected. He misrepresents the purpose and findings of the A\&E Primary Care Project at King's College Hospital, and his conclusion is fallacious.

The purpose of the King's project was "to compare consultations made by medical staff in the A\&E department and vocationally trained local GPs [general practitioners] for patients assessed as having primary care needs". ${ }^{2}$ Although our study was based in an inner city department, it is inaccurate for Cottingham to suggest that we see the use of the A\&E department by patients with primary care problems as just an inner city problem. Cottingham misinterprets the statement made in the report of the Royal Commission on the NHS in suggesting that the primary care use of $A \& E$ was seen as only an inner city problem, ${ }^{4}$ and he was wrong in suggesting that our study was intended to validate the Royal Commission's views.

We were also puzzled by why he suggests that we have "promulgated" the triage criteria we developed for our study. As we stated in our paper, "the development of a prospective method for identifying patients attending $A \& E$ with problems likely to be of a primary care type was a necessary step towards implementing service developments". "We have never suggested that the triage criteria are relevant outside this context.

It comes as no surprise to us that the primary care workload might be similar in some A\&E departments outside inner London to the levels found at King's. While we stated "a need to be cautious in considering the applicability [of the King's findings] to othe A\&E settings", ${ }^{2}$ we also argued that "the cost effectiveness [of employing GPs in A\&E] is likely to reflect not only the characteristics and experience of the GPs employed in these services but also a range of local circumstances, such as demand and management and operational issues. ${ }^{4}$

We find the last sentence of the final paragraph of the discussion and the conclusion illogical. Cottingham has demonstrated that by using our criteria the Eastbourne A\&E primary care workload is similar to that at King's. To conclude from this that our triage classification is not valid makes no sense. The only conclusion that can be derived from this study is that it provides evidence to support implementing an A\&E primary care service development at Eastbourne.

JEREMY DALE Professor of Primary Care, University of Warwich ED GLUCKSMAN Accident and Emergency Consultant King's Healthcare, King's College Hospital, Denmark Hill, London SE5 9RS

\section{The author replies}

Thank you for asking me to respond to the comments by Dale and Glucksman. There are a number of points which have been raised that I would like to address. With regards to their comment on resource utilisation, I did not collect data on resource use as we do not have a GP service within the A\&E unit. I describe their study as examining attendance patterns at their A\&E unit. ${ }^{1}$ Clearly this is part of the large important study, the Primary Care Project, but the point of the paper, as in their title, is the prospective identification of patients. I apologise if they feel that I have misrepresented their work; it was certainly not my intention so to do.

I have not suggested that Dale et al regard such use of services as an inner city problem. I wrote, "It is thought that such problems are worst in deprived areas of inner cities".' The existence of such problems seems to be a generally held view in the A\&E world and I have not attributed the statement to anyone.

I have quoted the Report of the Royal Commission on the NHS within the context of their paper and with reference to it. Their results and conclusions in my analysis seem to lead one to that conclusion.

To promulgate means simply to set forth or to publish; I am not sure why this causes puzzlement. As I explained, I have simply applied their criteria to my patient population.

I do not believe my conclusion to be nonsensical; since their paper has been published more precise tools have been developed that will lead to more accurate classification of patients. Perhaps we can agree to disagree. I am sure that Dale and Glucksman will agree that more research is essential into this very important area of patient preference.

1 Cottingham RL. Primary care problems in patients attending a semi-rural accident and emergency unit: a prospective study. J Accid emergency unit: a prospective

2 Dale J, Green J, Reid F, et al. Primary care in the accident and emergency department: I. Prospective identification of patients. BMJ 1995 311:423-6.

3 Dale J, Green J, Reid F, et al. Primary care in the accident and emergency department: II. comparison of general practitioners and hospital doctors. BMJ 1995;311:427-30.

4 Dale J, Lang H, Roberts J, et al. Cost effectiveness of treating primary care patients in accident and emergency: a comparison between general practitioners, senior house officers and registrars. BMJ 1996;312:1340-4.

\section{The early management of meningococca} disease

EDrTOR,-We commend the publication of a review of the early management of meningococcal disease. 'This is certainly a condition in which the doctors of first contact must have knowledge out of proportion to their previous experience. $^{2}$

It was disappointing, however, that this review focused on purpura as the sole cutaneous manifestation of meningococcaemia. It is almost universally recognised that a febrile tachycardic child with a purpuric rash should be treated as having meningococcal septicaemia. There was, however, no mention of les specific skin appearances of meningococcal disease in this review.

In a prospective study of meningococca disease presenting to hospital $13 \%$ had maculopapular rash only. ${ }^{3}$ The authors could not find any evidence that meningococcal disease presenting with a maculopapular rash alone was less severe than that presenting with purpura.

Another prospective study found 22 out of 126 children presenting with meningococcal disease had maculopapular rather than haemorrhagic rashes. ${ }^{4}$ This group reported a fata illustrative case of meningococcaemia misdiagnosed as measles in the presence of a maculopapular rash. The delayed or misdiagnosis of meningococcal disease in the presence of a maculopapular rash has been reported elsewhere.
The algorithm presented in the review offers false reassurance. The underlying message should be that the differential diagnosis of a toxic febrile child must include meningococcal disease whether they have a purpuric rash, a maculopapular rash, or no rash at all To take reassurance from the absence of purpura or petechiae shows a lack of understanding of the spectrum of presentation of meningococcal disease.

G L CAMPBELL-HEWSON Specialist Registrar in Emergency Medicin S M ROBINSON

Consultant in Emergency Medicine, Accident and Emergency Department Addenbrooke's Hospital, Cambridge $C B 22 Q Q$

1 Hodgetts TJ, Brett A, Castle N. The early management of meningococcal disease. J Accid Emerg Med 1998;15:72-6.

2 Welsby PD, Golledge CI. Meningococcal meningitis. BMJ 1990;300:1150-1.

3 Marzouk, O Thompson APJ, Sills JA, et al. Features and outcome in meningococcal disease presenting with maculopapular rash. Arch Dis Child 1991;66:485-7.

4 Riordan FAI, Thompson APJ, Sills JA, et al. Who spots the spots? Diagnosis and treatment of early meningococcal disease in children. BMJ 1996;313:1255-6.

\section{Ecstasy related trauma}

EDITOR,-Each year there are an estimated 50000 deaths and 1.5 million casualties as a result of road traffic accidents within the European Union, ${ }^{1}$ and it has been estimated that at least $10 \%$ of these victims have taken some form psychotropic medication that may have contributed to their accident. ${ }^{2}$ MDMA (3,4 methylenedioxymethamphetamine), widely known as ecstasy, is now cited as Europe's second most commonly used illicit drug and is likely to play a steadily increasing part in the aetiology of trauma. ${ }^{3}$ Over a three month period we treated 16 ecstasy abusers who had been injured as a result of road traffic accidents. Reckless driving was the cause of all accidents. Impaired mental function caused considerable difficulty in assessing neurological status in seven patients and the systemic effects of MDMA, including sinus tachycardia and pyrexia made general assessmerft problematic in 10. An array of serious injuries including 25 fractures were sustained by these patients. Eight who required acute surgery suffered no significant anaesthetic complications. We estimate the overall cost of hospital care for this group to be in excess of $£ 50000$.

We believe that greater public awareness of the risks of driving under the influence of MDMA is desirable and advise that accident and emergency staff familiarise themselves with the effects of this drug in order to safely assess and manage these patients.

J P DAVIES RO N EVANS D P NEWINGTON Morriston Hospital, Swansea

(Correspondence to: Mr J P Davies, 20 Ffordd Cwellyn, Cyncoed, Cardiff CF2 5NB)

1 De Gier J. Driving licences and known use of illicit drugs (IHP93-99). Maastricht: University of Limburg, Institute for Human Psychopharmacology, 1993.

2 European Commission. White paper on transport policy (COM 93-494). Brussels: European Commission, 1992.

3 United Nations. International Narcotics Control Board (INCB). Annual report. New York: UN, Board 1997. 